\title{
PENERAPAN MESIN ROLLING PIPA DI BENGKEL KNALPOT JALAN SETIABUDI SUMURBOTO SEMARANG
}

\author{
Nanang Budi Sriyanto ${ }^{1)}$, Adhy Purnomo ${ }^{2)}$, Ariawan Wahyu Putranto ${ }^{3)}$, Aryo \\ Satitoi ${ }^{4)}$, Eko Armanto5), Heru Saptono6), Sisworo ${ }^{7)}$, Suyadi ${ }^{8)}$, Ampala \\ Khoryanton") \\ 1,2,3,4,5,6,7,8,9) Jurusan Teknik Mesin, Politeknik Negeri Semarang \\ J1. Prof. H. Sudarto, S.H. Tembalang Semarang-50275 Kotak Pos 6199/SMS \\ Telp: (024) 7473417, 7499585-87, 7478727 (hunting) Fax: (024) 7472396 \\ Website: http://www.polines.ac.id Email : sekretariat@ polines.ac.id
}

\begin{abstract}
Exhaust repair shop J1. Setiabudi No. 36, Sumurboto, Banyumanik, Semarang was founded by Mr. Eko Budiyono. The workshop is a small and medium-sized enterprise engaged in the manufacture and repair of exhausts with four employees. Productivity in a month can produce 10 pieces of exhaust with an income of twenty million rupiah per month. Armed with his skills and simple equipment, a car exhaust was done with satisfactory results. The assistance that the UKM needs from the University is a pipe rolling machine tool that can be used to bend the pipe size of a motorbike exhaust. The plan to be implemented to achieve this goal is to provide science and technology grants in the form of a pipe rolling machine and provide training related to the machine. The mentoring process will be carried out for 4 months. The awarding of the pipe rolling machine is expected to contribute to UKM. This exhaust manufacturing business is expected to provide new jobs for the surrounding community, so that economic growth will increase. This community service also involves students majoring in Mechanical Engineering POLINES for social learning and supporting final assignments.
\end{abstract}

Key words: workshop, exhaust manufacturing, exhaust repair, granting machine, rolling engine

\begin{abstract}
Abstrak
Bengkel knalpot Jl. Setiabudi No. 36, Kelurahan Sumurboto, Kecamatam Banyumanik, Semarang di dirikan oleh Bapak Eko Budiyono. Bengkel tersebut termasuk usaha kecil menengah yang bergerak dalam pembuatan dan perbaikan knalpot dengan empat orang karyawan. Produktifitas dalam sebulan bisa menghasilkan 10 buah knalpot dengan mendapat penghasilan mencapai sepuluh juta hingga dua puluh juta rupiah per bulan. Keterbatasan mesin yang ada tidak mengurangi hasrat Eko Budiyono untuk menjadi wirausahawan. Berbekal modal skill yang dimilikinya dan dengan peralatan sederhana, suatu knalpot mobil di kerjakan dengan hasil yang cukup memuaskan. Bantuan yang diperlukan UKM tersebut dari Perguruan Tinggi adalah peralatan mesin rolling pipa yang dapat digunakan untuk menekuk pipa ukuran knalpot motor. Rencana yang akan dilaksanakan untuk mencapai tujuan tersebut adalah dengan memberikan hibah iptek berupa mesin rolling pipa dan memberikan pelatihan-pelatihan yang berhubungan dengan mesin tersebut. Proses pendampingan akan dilakukan selama 4 bulan. Penghibahan mesin rolling pipa ini diharapkan dapat memberikan kontribusi pada UKM, Usaha pembuatan knalpot ini diharapkan akan memberikan lapangan kerja baru bagi masyarakat sekitar, sehingga pertumbuhan ekonomi akan meningkat. Pengabdian kepada masyarakat ini juga melibatkan mahasiswa jurusan Teknik Mesin POLINES untuk pembelajaran sosial dan mendukung tugas akhir.
\end{abstract}

Kata kunci: Bengkel knalpot, pembuatan knalpot, perbaikan knalpot, penghibahan mesin, mesin rolling 


\section{ANALISIS SITUASI}

Bengkel knalpot Jalan Setiabudi Semarang di dirikan oleh Bapak Eko Budiyono. Bengkel tersebut termasuk dalam kategori usaha kecil menengah yang bergerak dalam bidang pembuatan dan perbaikan knalpot kendaraan bermotor. Pada awalnya untuk membuat knalpot ia bekerja sendiri, tetapi setelah mulai banyak permintaan konsumen ia memperbantukan empat orang karyawan.



Gb. Baliho UKM

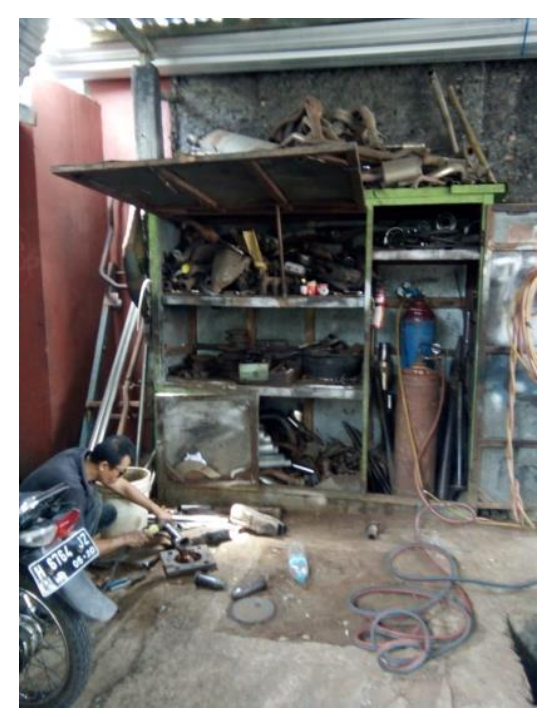

Gb. Bengkel knalpot Jalan Setiabudi

Produktifitas UKM tersebut dalam sebulan bisa menghasilkan 20 buah knalpot disamping setiap hari ada yang melakukan perbaikan. Dari usaha pembuatan dan perbaikan knalpot kendaraan bermotor tersebut penghasilannya mencapai sepuluh juta hingga dua puluh juta rupiah per bulan.

Mitra merupakan pengrajin industri yang bergerak dalam bidang jasa pembuatan dan perbaikan knalpot. Keberhasilan dalam usaha pembuatan knalpot ditentukan oleh skill operator dan peralatan yang digunakan. Keterbatasan mesin yang ada tidak mengurangi hasrat Eko Budiyono untuk menjadi wirausahawan. Berbekal modal skill yang dimilikinya dan dengan peralatan sederhana, suatu knalpot mobil di kerjakan dengan hasil yang cukup memuaskan. Meskipun terkendala besarnya modal dalam kepemilikan mesin, UKM mitra tetap berusaha menyelesaikan sebuah knalpot pesanan konsumen.

Kondisi Mitra

Bantuan yang bersifat pemberian teknologi, bimbingan dan pendampingan teknis dalam usaha pembuatan knalpot belum pernah dilakukan dari pihak manapun. Bantuan yang 
diperlukan UKM tersebut dari Perguruan Tinggi adalah bantuan peralatan mesin rolling pipa. Mesin rolling pipa ini dapat digunakan untuk membuat/ menekuk pipa ukuran knalpot motor dan sesuai digunakan untuk meningkatkan produksi. Knalpot motor hasil produk mesin ini diharapkan dapat mengatasi permasalahan yang di hadapi UKM sedemikian rupa sehingga kualitas dan kuantitasnya semakin meningkat.

\section{PERSOALAN YANG DIHADAPI MITRA}

Peralatan/ mesin rolling yang di gunakan untuk pembuatan knalpot hanya bisa untuk menekuk pipa-pipa knalpot mobil, sehingga proses produksi lebih banyak pada knalpot mobil. Modifikasi dan perbaikan juga lebih banyak pada knalpot mobil sehingga dalam sebulan bisa menyelesaikan sampai 80 gendangan knalpot mobil.

Beberapa langkah rencana yang akan dilaksanakan untuk mencapai tujuan tersebut adalah dengan memberikan hibah iptek berupa mesin rolling pipa dan memberikan pelatihan-pelatihan yang berhubungan dengan mesin tersebut. Proses pendampingan akan dilakukan selama 4 bulan. Hal ini dilakukan untuk memastikan bahwa projek berjalan dengan lancar. Penghibahan mesin rolling pipa ini diharapkan dapat lebih memberikan kontribusi pada UKM, dan masyarakat setempat termotivasi untuk mulai membuat usaha baru, sehingga akan menambah tenaga kerja. Usaha pembuatan knalpot akan memberikan lapangan kerja baru bagi masyarakat sekitar, sehingga pertumbuhan ekonomi akan meningkat. Pengabdian ini juga melibatkan mahasiswa jurusan Teknik Mesin POLINES untuk pembelajaran sosial dan mendukung tugas akhir.

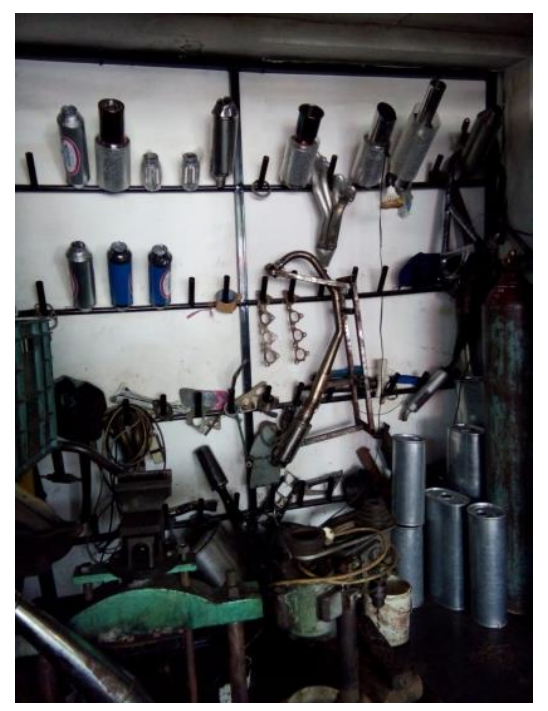

Gb. Gendangan knalpot mobil buatan mitra ready stock 
Pembuatan sambungan dan pemotongan pipa knalpot yang bocor menggunakan mesin las karbit, sedangkan mesin rolling pipa digunakan menyelesaikan gendangan knalpot mobil 40 sampai 80 tiap bulannya.

\section{DATA KUALITATIF DAN KUANTITATIF MITRA}

UKM Bengkel Knalpot pada saat ini menempati bengkel kerja, di Jalan Setiabudi Semarang. Mesin merupakan kebutuhan dasar dan salah satu faktor terpenting dalam usaha pembuatan sebuah knalpot. Keberhasilan dalam usaha pembuatan sebuah knalpot ini ditentukan oleh skill operator disamping mesin pruduksi yang kompetibel. Setiap minggu mitra baru mampu menghasilkan 10 sampai 20 gendangan knalpot, sehingga dalam satu bulan Bengkel Knalpot Jalan Setiabudi Semarang kurang lebih hanya bisa menyelesaikan 40 (empat puluh) hingga 80 (delapan puluh) gendangan knalpot.

Harga sebuah gendangan knalpot berkisar Rp. 400000 (empat ratus ribu rupiah) hingga Rp. 800000 (delapan ratus ribu rupiah), yang berarti bruto tiap bulan mencapai enam puluh juta an rupiah. Gaji empat orang karyawan Rp. 10000000 (sepuluh juta rupiah) dan untuk biaya bahan baku Rp. 10.000 .000 (sepuluh juta rupiah), sewa tempat Rp. 15.000.000 (lima belas juta rupiah), biaya lainnya lima juta rupiah sehingga sebagai pemilik Eko Budiyono bisa mendapatkan netto Rp. 20.000.000 (dua puluh juta rupiah) per bulan.

\section{PERMASALAHAN MITRA}

Hasil kunjungan pertama tim pengabdian ke lokasi mendiskusikan permasalahan yang di alami mitra dan bersepakat untuk menyelesaikan dengan topik PKM (Program Kemitraan Masyarakat) agar diselesaikan.

Permasalahan mitra tersebut pada dasarnya adalah:

Ingin meningkatkan kualitas produk knalpot

Ingin meningkatkan kuantitas dan diversifikasi produk knalpot

Ingin mendapatkan penghibahan mesin dari Perguruan Tinggi

Bantuan yang bersifat pemberian teknologi, bimbingan dan pendampingan teknis dalam usaha pembuatan knalpot belum pernah dilakukan dari pihak manapun. Bantuan yang diperlukan UKM tersebut dari Perguruan Tinggi adalah bantuan peralatan mesin rolling pipa. Mesin rolling pipa ini sangat cocok digunakan oleh Bengkel Knalpot Jalan 
Setiabudi Semarang untuk meningkatkan produksi. Knalpot hasil produk dari mesin ini diharapkan dapat mengatasi permasalahan yang di hadapi Bengkel sedemikian rupa sehingga kualitasnya semakin baik.

\section{MAKNA EKSISTENSI MITRA DI LINGKUNGAN MASYARAKAT}

Usaha kecil menengah Bengkel Knalpot Jalan Setiabudi Semarang banyak memberikan manfaat bagi masyarakat disekelilingnya. Manfaat tersebut adalah sebagai berikut.

1) Memberikan kontribusi kesejahteraan bagi masyarakat di sekeliling

2) Memberi motivasi masyarakat setempat untuk membuat usaha baru

3) Menyerap tenaga kerja

Inovasi mesin rolling pipa untuk produksi knalpot diharapkan dapat lebih memberikan kontribusi pada bengkel knalpot Jalan Setiabudi, Semarang dan masyarakat setempat termotivasi untuk mulai membuat usaha baru, sehingga akan menambah tenaga kerja. UKM akan dapat membuat produksi knalpot lebih banyak dengan variasi bahan yang sesuai dan dapat menekan harga produk impor.

\section{SOLUSI PERMASALAHAN}

Mitra termasuk kategori pengusaha kecil dalam bidang produksi knalpot, sehingga perlu dilakukan pendampingan secara intensif yang disetujui bersama. Langkah-langkah yang ditawarkan seperti pada tabel 1 dan diharapkan dapat mencapai hasil serta tujuan dari skim bantuan PKM tahun 2019.

Tabel 1 Permasalahan mitra dan langkah penyelesaian tim pengabdian

\begin{tabular}{|l|l|l|l|}
\hline No & Masalah & Tawaran Solusi & Fasilitator \\
\hline 1 & Peningkatan kualitas pr & $\begin{array}{l}\text { Penyuluhan tentang pengoper: Tim pengabdian Polines } \\
\text { mesin rolling pipa dan pela } \\
\text { proses produksi }\end{array}$ & \\
\hline 2 & $\begin{array}{l}\text { Peningkatan } \\
\text { produk }\end{array}$ & Pengadaan mesin rolling pipa & Tim pengabdian Polines \\
\hline
\end{tabular}

\section{DAFTAR LUARAN}

1 Publikasi Ilmiah Jurnal Nasional Tidak Terakreditasi Target accepted/published

2 Media Lokal Target sudah terbit/sudah dilaksanakan 
3 Video kegiatan Target sudah/ada

4 Keterampilannya meningkat Target sudah/ada

\section{METODE PELAKSANAAN}

Mitra yang bergerak di bidang produksi Knalpot termasuk kategori pengusaha kecil ekonomi produktif dan mengarah ke ekonomi produktif, sehingga perlu dilakukan pendampingan secara intensif yang disetujui bersama. Langkah-langkah pelaksanaan dalam kegiatan diharapkan dapat mencapai hasil dan tujuan dari skim bantuan PKM tahun 2019.

Metode yang digunakan dalam kegiatan pengabdian kepada masyarakat tahun 2019 ini adalah sebagai berikut :

1. Tahap Perencanaan:

- Sosialisasi program kemitraan

- Koordinasi tim pelaksana

- Pembuatan modifikasi peralatan mesin

2. Tahap Pelatihan

Materi tentang pelatihan teknik pengoperasian mesin

3. Tahap Evaluasi

- Evaluasi untuk mengetahui tingkat keberhasilan

4. Tahap penerapan

Tahap penerapan di bengkel kerja yang dilakukan oleh operator/ karyawan yang sudah mengikuti pelatihan teknik pengoperasian mesin

\section{KELAYAKAN PERGURUAN TINGGI}

Pengalaman Politeknik Negeri Semarang dalam Penerapan IPTEK

Politeknik Negeri Semarang sebagai perguruan tinggi mengemban tiga dharma, yaitu :

1. Pendidikan

2. Penelitian dan

3. Pengabdian kepada Masyarakat

Dalam meniti karirnya, para dosen di perguruan tinggi harus melaksanakan ketiga dharma tersebut termasuk pengabdian kepada masyarakat. Karena itu, Politeknik Negeri Semarang mempunyai unit khusus yang menangani kegiatan pengabdian kepada 
masyarakat tersebut, sehingga Politeknik Negeri Semarang sebagai perguruan tinggi sangat layak untuk melaksanakan kegiatan pengabdian kepada masyarakat dengan target luaran mesin rolling pipa yang akan di hibahkan.

\section{HASIL YANG DICAPAI}

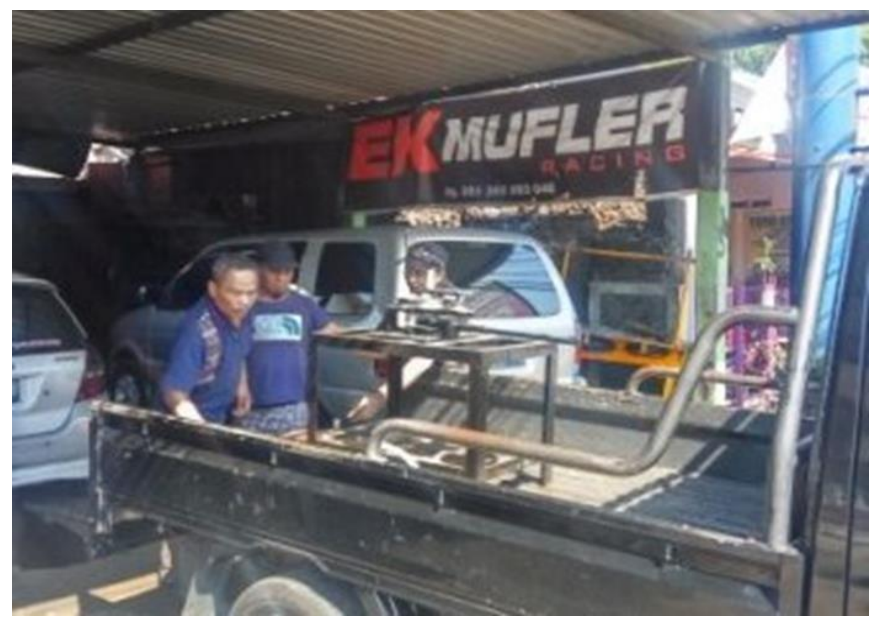

Pengiriman mesin rolling pipa ke bengkel knalpot jalan setiabudi sumurboto semarang



A

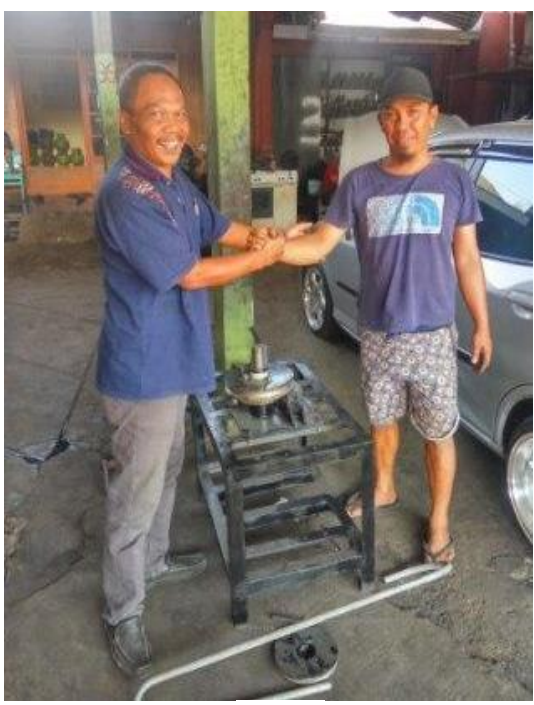

$\mathrm{B}$

A Penjelasan cara kerja mesin rolling pipa

B Serah terima penghibahan mesin rolling pipa 


\section{SIMPULAN}

Alat rolling pipa ini mempunyai spesifikasi:

Nama mesin : Alat Rolling Pipa

Penggerak putaran: Roda Gigi dengan Reducer 1:3.

Dimensi $\quad: 300 \mathrm{~mm} \times 300 \mathrm{~mm} \times 230 \mathrm{~mm}$

Mitra UKM bengkel knalpot jalan Setiabudi Sumurboto Semarang sangat terbantu dengan adanya bantuan hibah mesin rolling pipa guna meningkatkan kinerja bengkel yang di kelola

\section{DAFTAR PUSTAKA}

1. http://ergonomi-fit.blogspot.co.id/2011/06/maksimum-berat-beban-ergonomi.html (Diakses tanggal 28 Agustus 2016. Jam 21.43)

2. http://fisikazone.com/momen-gaya-dan-momen-kopel/ (Diakses tanggal 28 Agustus 2016. Jam 21.55)

3. http://aljabarsquad.blogspot.co.id/2012/08/kekuatan-bahan-tarikan-desakan-dan.html (Diakses tanggal 28 Agustus 2016. Jam 22.12)

4. Novandra D R, dkk, 2015, Rancang bangun roll bending machine dengan sistim hidroaulic sebagai penggerak roll dan transmisi menggunakan rantai serta menggunakan gearbox reducer 1:60 PPNS Jounal 